\title{
MOTIVATION OF THE STUDENTS FROM TRAKIA UNIVERSITY FOR PARTICIPATION IN PHYSICAL EDUCATION CLASSES
}

\author{
P. Petkov* \\ Department of Physical Education and Sport, Trakia University, Stara Zagora, Bulgaria
}

\begin{abstract}
The aim of the present study is to examine the motivation of students from Trakia University to participate actively in physical education classes and sports. A survey as an express method of assessing students' motivation for sports activities is conducted. Different aspects of their sports interests are studied. It is established that students have positive attitude towards physical education classes and sports. Insufficient awareness of students with regard to all the benefits of practicing physical exercises and sports is registered. Because of the high demand during the educational process, students do not have enough free time for additional sports activities. Based on the obtained results, the following recommendations are proposed: to create conditions for inclusion of all students in additional sports; students to obtain theoretical knowledge on the use, effects and benefits of practicing physical exercises and sports; students to acquire knowledge and skills for individual sports activities, and to improve and upgrade the facilities of the university.
\end{abstract}

Key words: survey, circuit training, interests

\section{INTRODUCTION}

The continuous development of science, technical progress, the increasing amount of information used by students and other factors influence the nature of the learning process in higher education institutions. For the successful realization in life during their education, students must master their professional knowledge and skills thoroughly and thoroughly. Their daily lives are becoming more intense and tense, and their educational obligatory is constantly increasing. Students' educational and work activities are in a uniform posture and insufficient motoring regime, which in turn leads to immobilization, emotional and neuro-mental tension, chronic fatigue, stressful conditions, lowering physical fitness and increasing the risk of various diseases (1).

The issue of health of the younger generation, their physical activity and physical capacity is becoming more and more relevant. Sports activities are an alternative to these harmful phenomena. They stimulate mental capacity, work activity, metabolic processes in the body and are a factor in strengthening health and increasing resistance to illness (2-3).

\footnotetext{
*Correspondence to: P. Petkov, Department of Physical Education and Sport, Trakia University, Trakia University, Students Campus, 6000 Stara Zagora, Bulgaria, E-mail: jo_team@abv.bg
}

In recent years, there are specialized publications devoted to exploring the interests and role of physical activity of students to improve their health and mental capacity (4-7). For the effective implementation of the physical and sport education process, a psychological readiness is required, linked to a pre-formed attitude towards upcoming activity in classes and a properly articulated attitude to the role and importance of sport.

Psychology treats attitude as a system of persistent predominant motives of human behavior. They express the attitude of man to the object of action and are the basis of his actions. The formation and development of attitudes to sporting activities are influenced by various social factors and the interrelationships between them. Family, school and the environment, the organization and content of classes, the personality of the student, the qualities of the lecturer, etc., can influence these processes. Motivation is a mental mechanism that determines the tendency of an individual to be active in a selective and organized way, and is related to the satisfaction of certain needs (9).

The aim of the present study is to investigate the motivation of students at Trakia University to participate actively in the classes of Physical 
Education and Sport. To accomplish the goal, the following tasks were set:

1. development of a questionnaire;

2. performance of a survey;

3. processing and analyses of the data from the survey.

\section{METHODS}

1. Questionnaire survey

2. Mathematical methods

The survey was conducted during the winter semester of the academic 2016/2017 year. The control group of the study consisted 84 students (men) aged 20-23 years from the
Faculty of Agriculture, Faculty of Veterinary Medicine and Faculty of Economics at Trakia University, Stara Zagora, Bulgaria. The poll was anonymous. The questionnaire contained 17 questions and 4 sub-questions.

\section{RESULTS AND DISCUSSION}

After processing the data from the survey, the following results were obtained. To the question - "Do you like Physical Education?" a sufficiently high percentage $(98.81 \%)$ of respondents answered positively and only $1.19 \%$ responded negatively. The results are presented graphically in Figure 1.

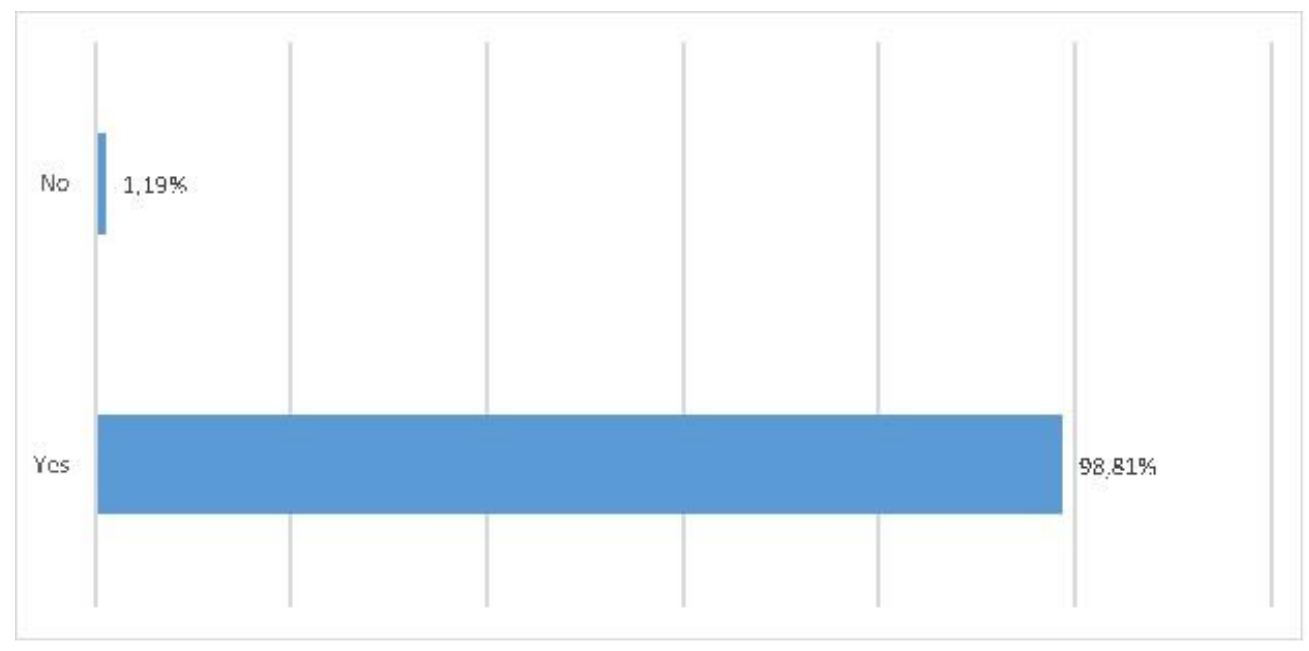

Figure 1: Answers to the question „How do you evaluate physical education classes?"

On the question - "How do you evaluate physical education classes?" - 78.57\% find physical education and sports classes interesting, $17.86 \%$ - uniform, according to $3.57 \%$ they were boring. For a fairly large number of students, the physical education and sports curriculum is interesting, but judging from the answers of almost $22 \%$ of the respondents, they seem to be boring. Thus, it may be considered to diversify this curriculum. The results are presented graphically in Figure 2.

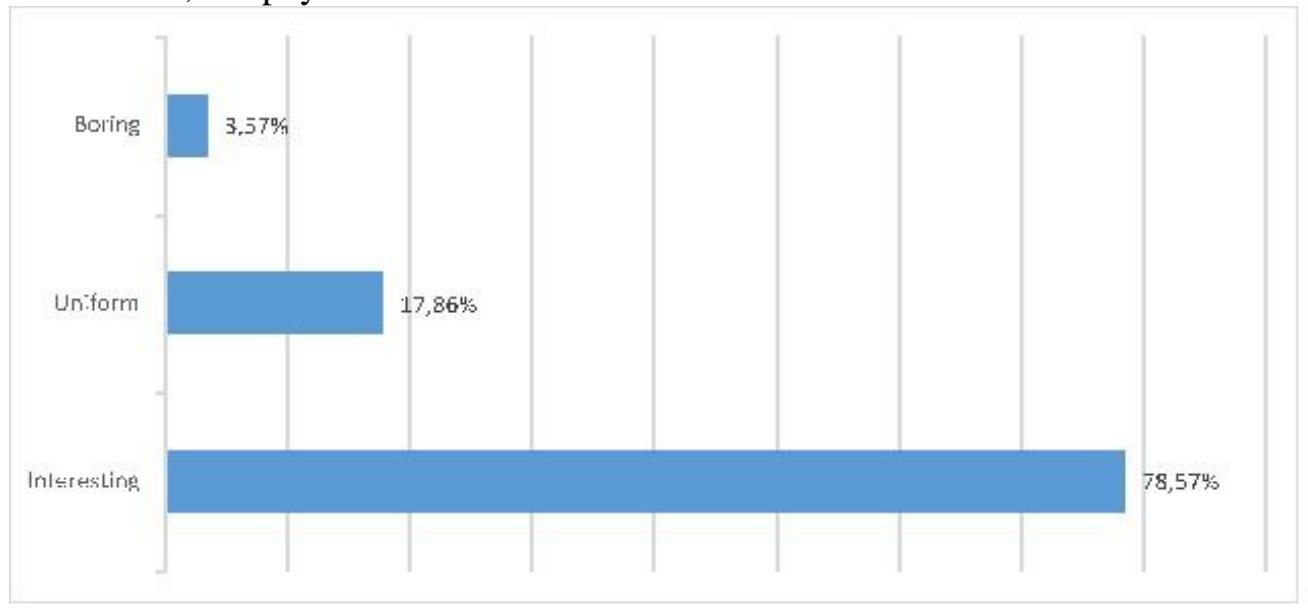

Figure 2: Answers to the question „How do you evaluate physical education classes?”

To the question - "Do you think that the number of physical education and sports classes at the University is sufficient?" $72.62 \%$ responded that the hours of Physical
Education and Sport were enough, according to $23.81 \%$ of the students they were not enough, and $3.57 \%$ can not judge. The results are presented graphically in Figure 3. 


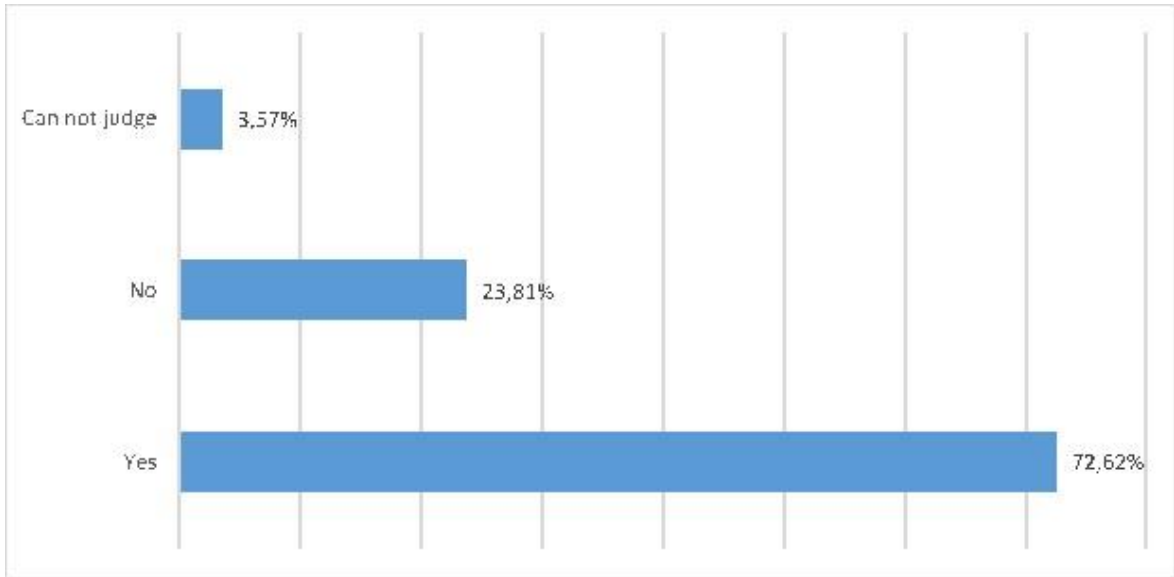

Figure 3: Answ ers to the question „Do you think that the number of physical education and sports cla sses at the Univer sity is sufficient?"

To the question - "Do you participate actively in Physical Education classes?" - 97.62\% of the students are actively involved and only $2.38 \%$ do not participate actively in the physical education and sports classes. Obviously, almost all students are actively participating in the classes and only $2.38 \%$ do not participate actively, indicating that they are not interested, do not want to be burdened, and do not see any meaning in this subject. The results are presented graphically in Figure 4.

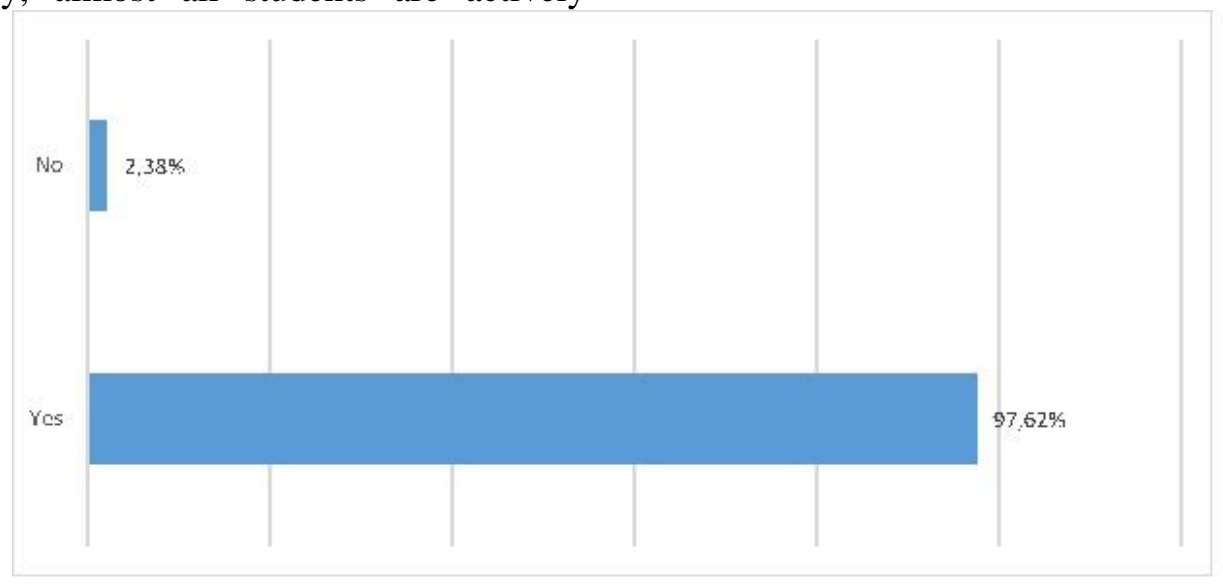

Figure 4: Answ ers to the question „Do you participate actively in Physical Education cla sses?”

To the question - "Is it enough for you to load in Physical Education classes?" - 85.71\% of the workload is enough and according to $14.29 \%$ of the students it was not enough. The fact that $85.71 \%$ of students are loaded enough in Physical Education and Sports. These results prove that the intensity and density of the classes are very good and the load is enough. The results are presented graphically in Figure 5.

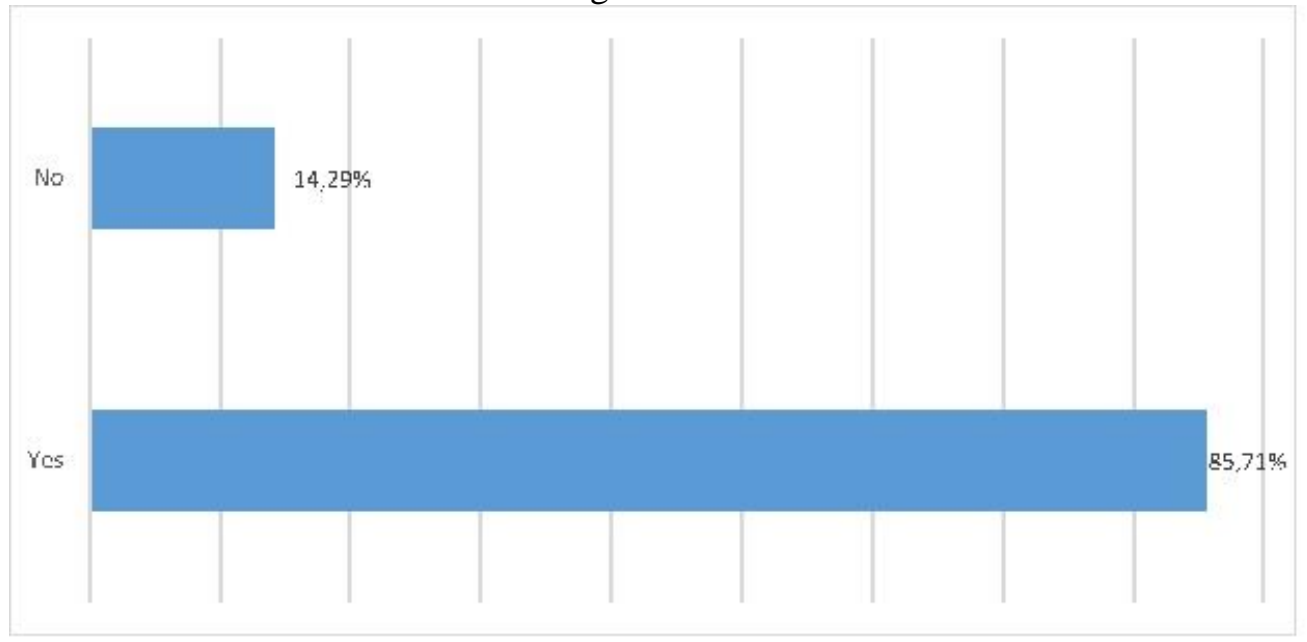

Figure 5: Answ ers to the question „Is it enough for you to load in Physical Education classes?" 
To the question: "Are the knowledge and skills gained during the Physical Education hours useful for your future activity in the specialty?" $-39.29 \%$ of the students are convinced that the knowledge and skills they will acquire will be necessary in their professional career, $29.76 \%$ suggest that they will be more useful, $25 \%$ consider that they will not be useful and 5.95\% are sure that none of the lessons learned in the physical education and sports classes will be useful in their future profession. The results are presented graphically in Figure 6.

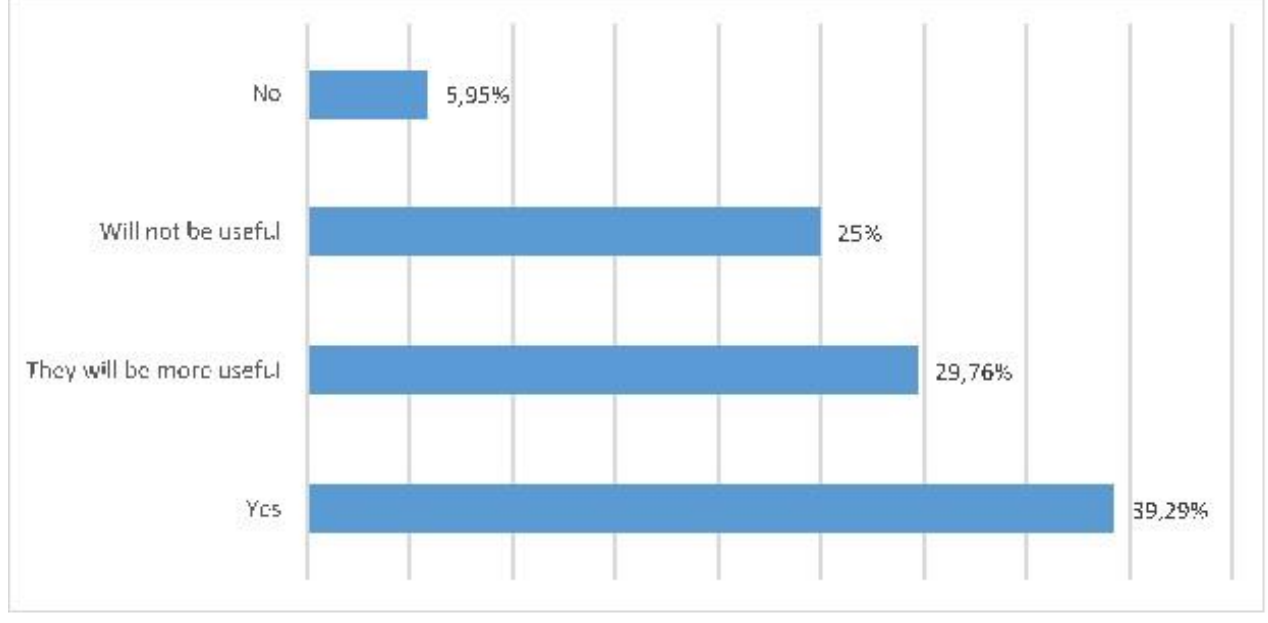

Figure 6: Answers to the question „Are the know ledge and skills gained during the Physical Education hours usful for your future activity in the specialty?"

On the question - "What do you think about physical education?" - the students believe that they improve the physical capacity (72.62\%), strengthen the health and increase the resistance of the organism (76.19\%), improve the body status $(65.48 \%)$, prepare them better for their future profession (14.29\%), give knowledge about self-exercise $(21.43 \%)$. The percentages are above $100 \%$ because the students have given more than one answer. The

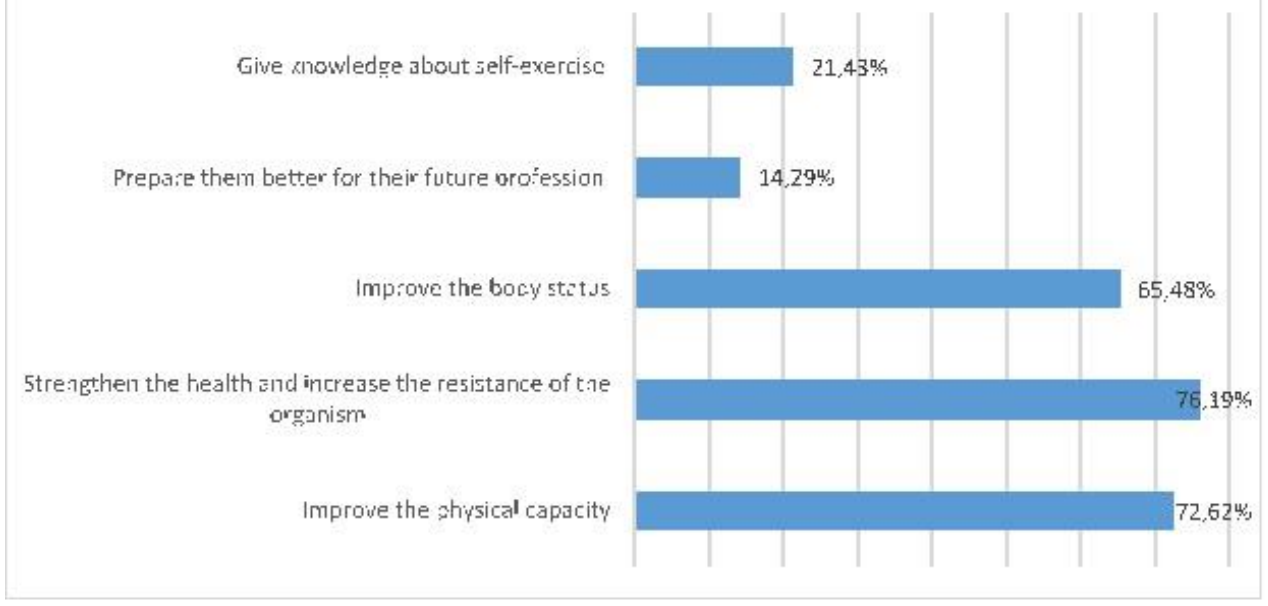

Figure 7: Answers to the question ,W hat do you think about physical education?"

The question - "Suppose you have more free time. How would you use it? "- $19.05 \%$ would use their free time to go to cinema, theater or opera, $29.76 \%$ will study and read more books, $63.10 \%$ will sport more, $32.14 \%$ would travel more, $15.48 \%$ will spend more time on the computer, $7.14 \%$ will watch more TV, $33.33 \%$ will enjoy more, $15.48 \%$ will go to restaurants, $1.19 \%$ gave another answer (work and extra income). The percentages are more than $100 \%$ data show that $14.29 \%$ of the students do not know that through physical education they can develop skills and habits to form behavioral responses that predetermine the success of their professional activities in the future. According to the majority of students, physical education is improving physical status and strengthening health. The results are presented graphically in Figure 7. because the students gave more than one answer. Obviously, a very large percentage of students want to do sports in their free time $(63.10 \%)$. But when we asked them to prioritize them, only $30.95 \%$ put the sport first. $47.14 \%$ have first placed reading books, $6.02 \%$ will travel, $3.67 \%$ will watch $\mathrm{TV}, 3.58 \%$ will go to cinema, theater or opera, $3.02 \%$ will spend time on the computer, $2 \%$ will rest longer, $2.1 \%$ will work more, $1.52 \%$ will go to 
restaurants. In comparison, in 2011 the students from the University of National and World Economy indicated the following priority activities $-32 \%$ will work, $28 \%$ will work for additional income, $18 \%$ will spend time on the computer, $16 \%$ will attend cultural events, $1 \%$ will go to restaurants and $5 \%$ prefer another occupation. The results are presented graphically in Figures 8 and 9.

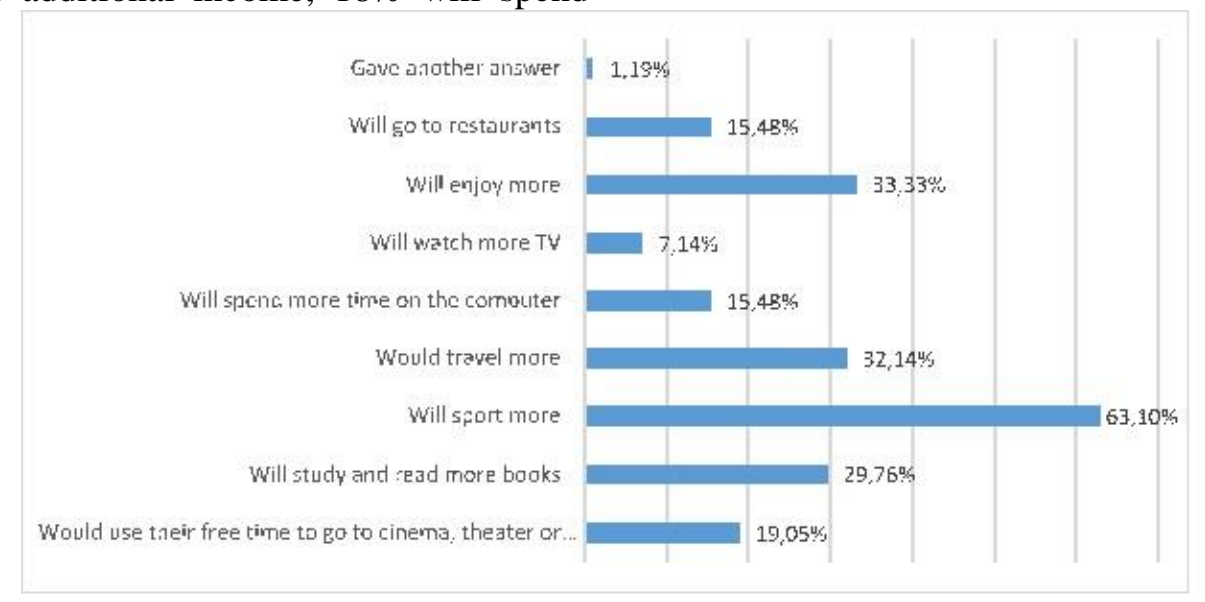

Figure 8: Answers to the question „Suppose you have more free time. How w ould you use it?”

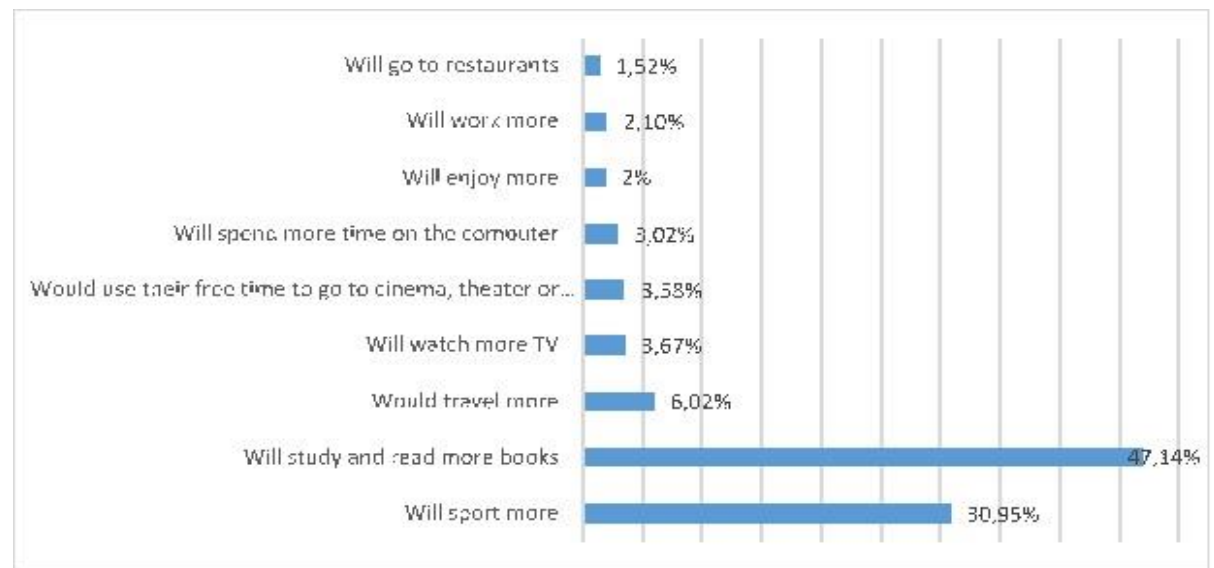

Figure 9: Answ ers to the question „Arrange activities by priority”

To the question - "If there are free elective courses in Physical Education, would you attend them?" - 78.57\% of the students would attend freely elective classes. They would like to load extra. $21.43 \%$ would not attend such classes. According to these students, their weekly physical load is sufficient or they are unwilling to be engaged in sports. The results are presented graphically in Figure 10.

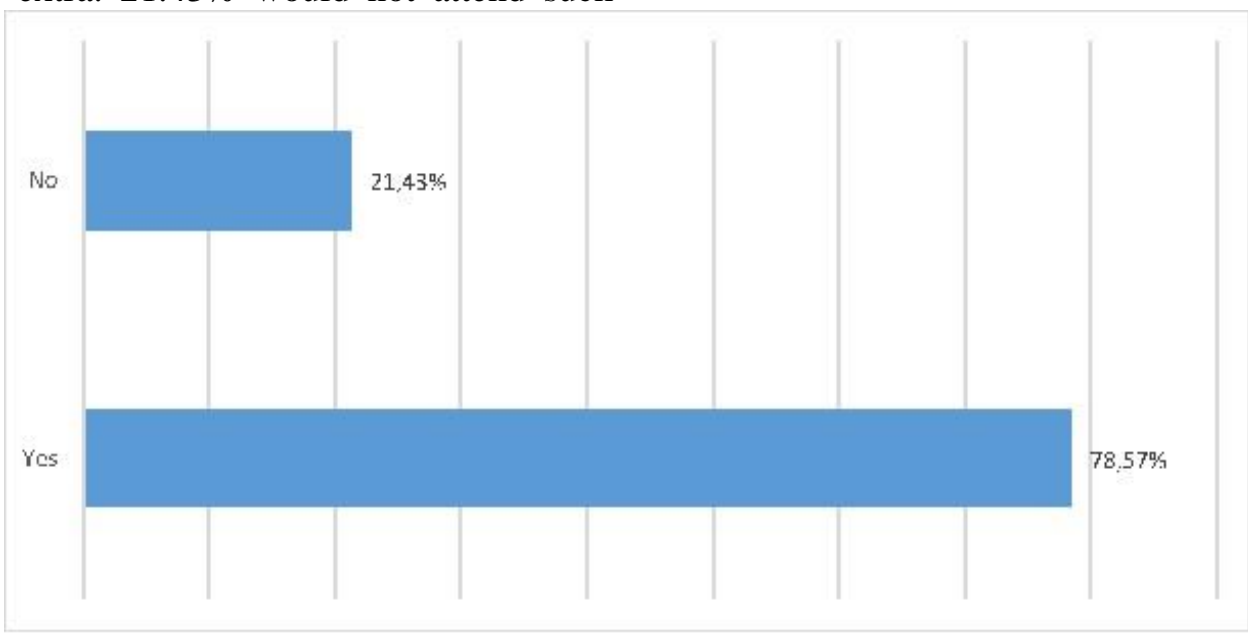

Figure 10: Answers to the question ,If there are free elective courses in Physical Education, would you attend them?" 
On the question, "What would you like to change or be covered in Physical Education classes in order to raise your interest?" according to most of the students no change in classes is required; Recommendations include the following: improving facilities, more sports engagement, and including other sports in physical education.

On the question - "Have you been involved in sports?" $-65.48 \%$ of the students interviewed were involved in sports before starting their studies at Trakia University and $34.52 \%$ of them were not. Athletes have been involved in football, fitness and basketball. The other sports they practiced were volleyball, martial arts, boxing, fencing, etc. Currently, the percentage of sporting students has decreased to $42.86 \%$, and that of non-sportsmen have increased to $57.14 \%$. Sporting students are mostly engaged in fitness and less sport. They practice the chosen sport up to three times a week $(22.62 \%)$ and more than three times a week $-77.38 \%$ of the students. On a similar question from a survey conducted at the University of National and World Economy in $2011,74 \%$ of the students were engaged in sports and only $26 \%$ do not exercise during their studies. $70 \%$ of them practice sport at least three times a week and $30 \%$ - less than three times a week. From these comparisons, it is clear that the students practicing sports have almost halved. This fact is rather disturbing because, due to the heavy workload in the learning process, students do not succeed or do not want to be engaged in sports activities that would greatly provide them with a very good active rest, recovery of the spent mental and emotional forces and etc. The results are plotted in Figures 11, 12 and 13.

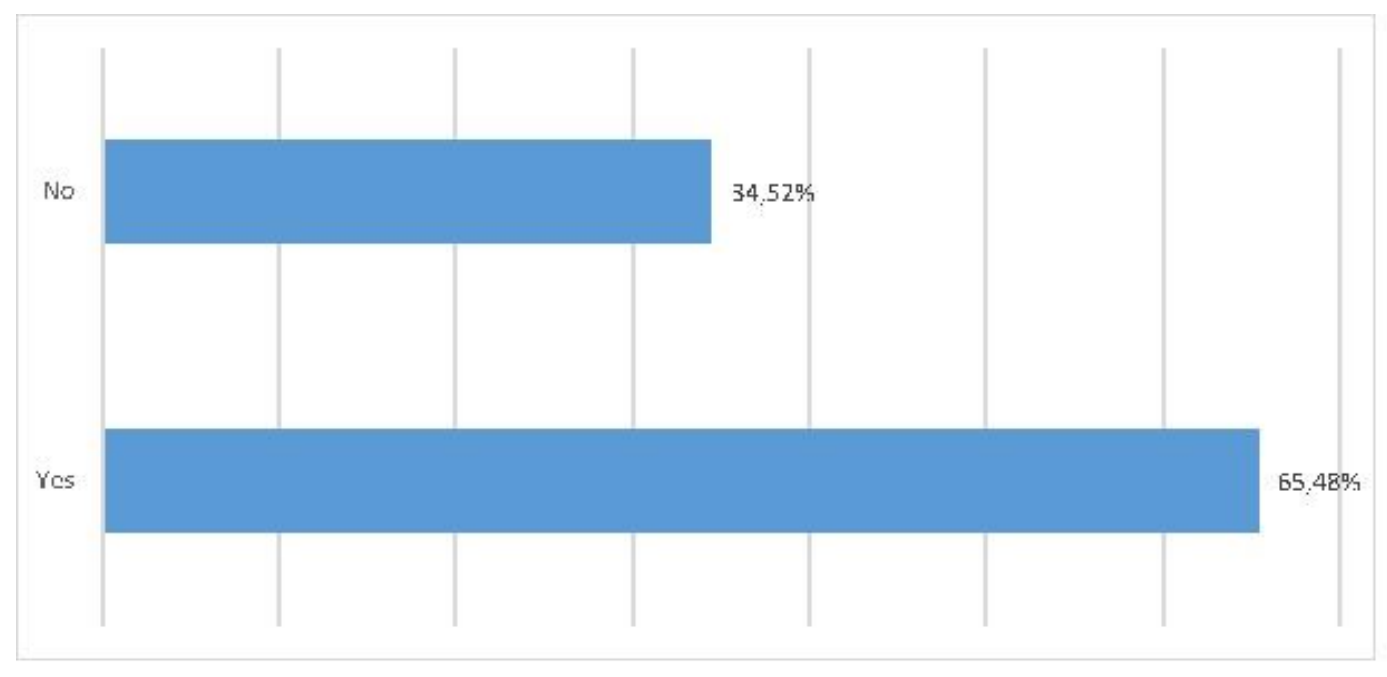

Figure 11: An swers to the question „Have you been involved in sports?”

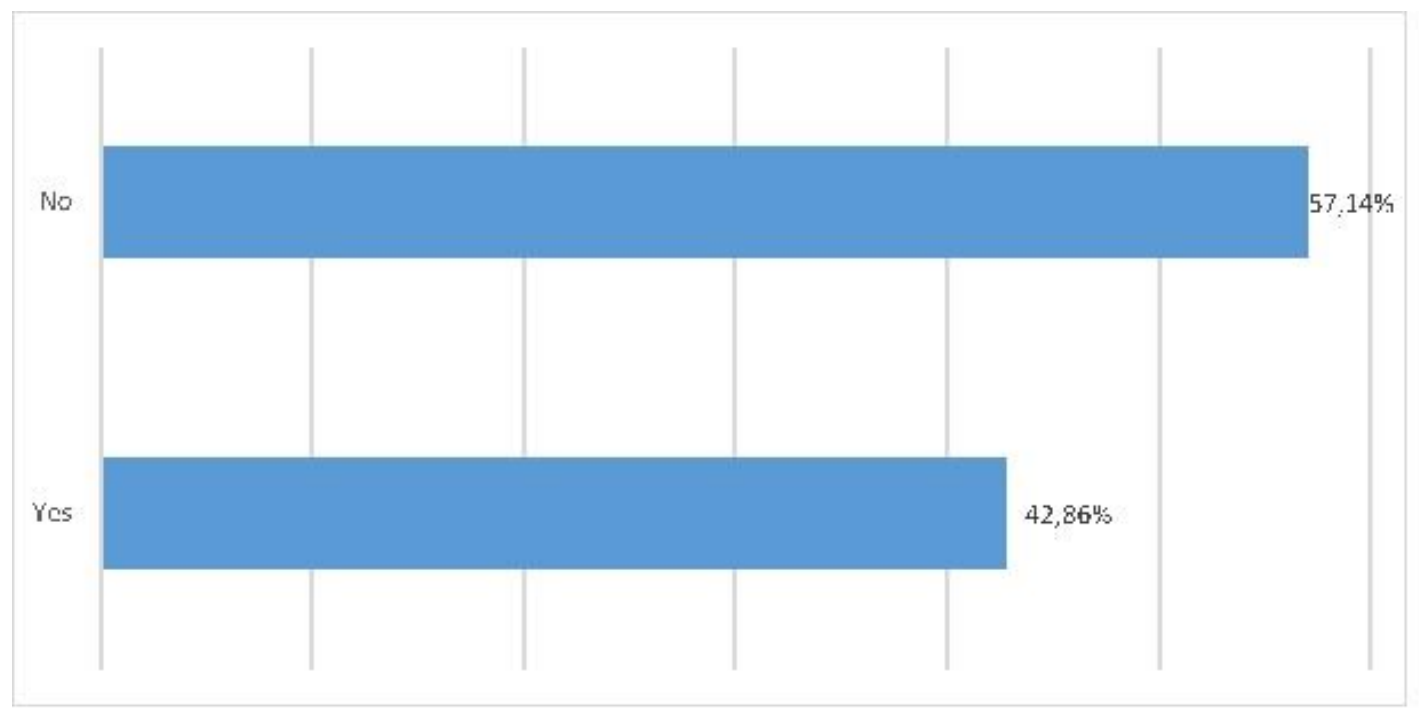

Figure 12: An swers to the question „Do you have a sport right now?" 


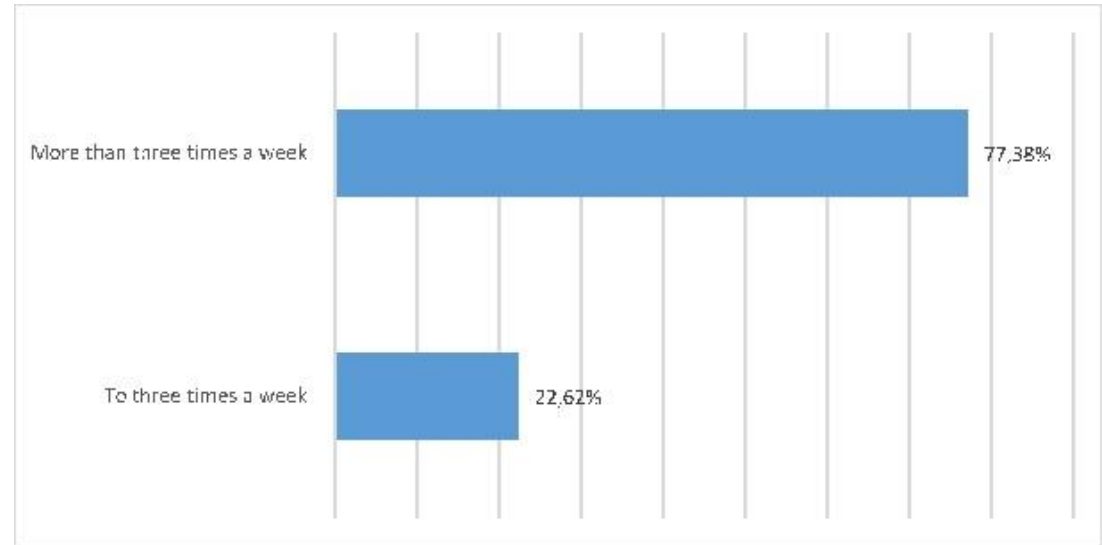

Figure 13: Answers to the question „How many times a w eek do you sport?”

To the question - "Does the improvement of your appearance motivates you to do sports?" a large part of the students $(64,29 \%)$ are motivated for their appearance, for $32,14 \%$ of them the appearance is not a priority; $3.57 \%$ have indicated another reason, such as selfesteem and pleasure. In comparison, students from the University of National and World Economy in 2011 gave the following answers:
$45 \%$ answered positively, $49 \%$ responded negatively and $6 \%$ could not judge. The large number of positive responses gives us reason to suppose that there are some prejudices about the appearance and public opinion of a large number of people willing to be engaged in sport. The results are presented graphically in Figure 14.

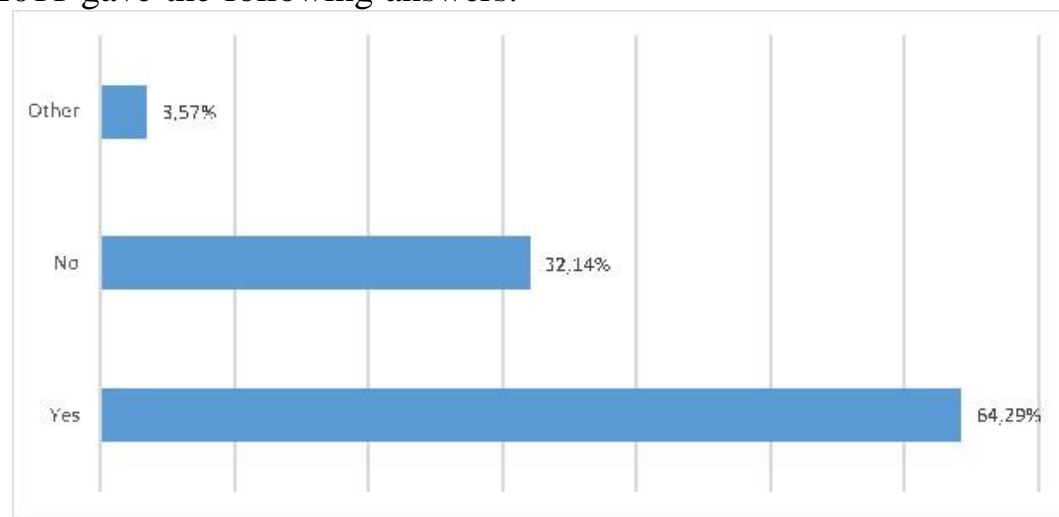

Figure 14: Answers to the question „, Does the improvement of your appearance motivates you to do sports?"

On the question - "How would you keep your figure?" - $19.05 \%$ will maintain their figure through diets, $58.33 \%$ of the students would use strength training and $19.05 \%$ will use cardio workouts to support their figure, 3 , 57\% have indicated other options. The results are presented graphically in Figure 15.

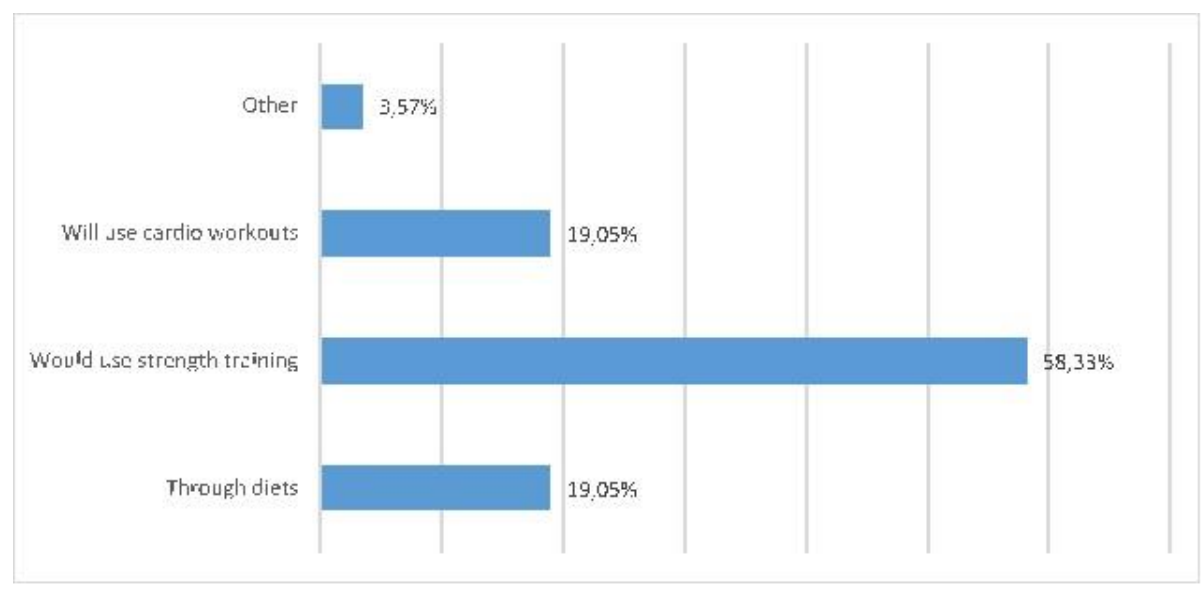

Figure 15: Answers to the question „How would you keep your figure?” 
To the question - "Did you use circular workouts?" - $48.81 \%$ of the students used circular exercises in their sports activities, and the remaining $51.19 \%$ never used this type of workout in their sports activities. The results are presented graphically in Figure 16.

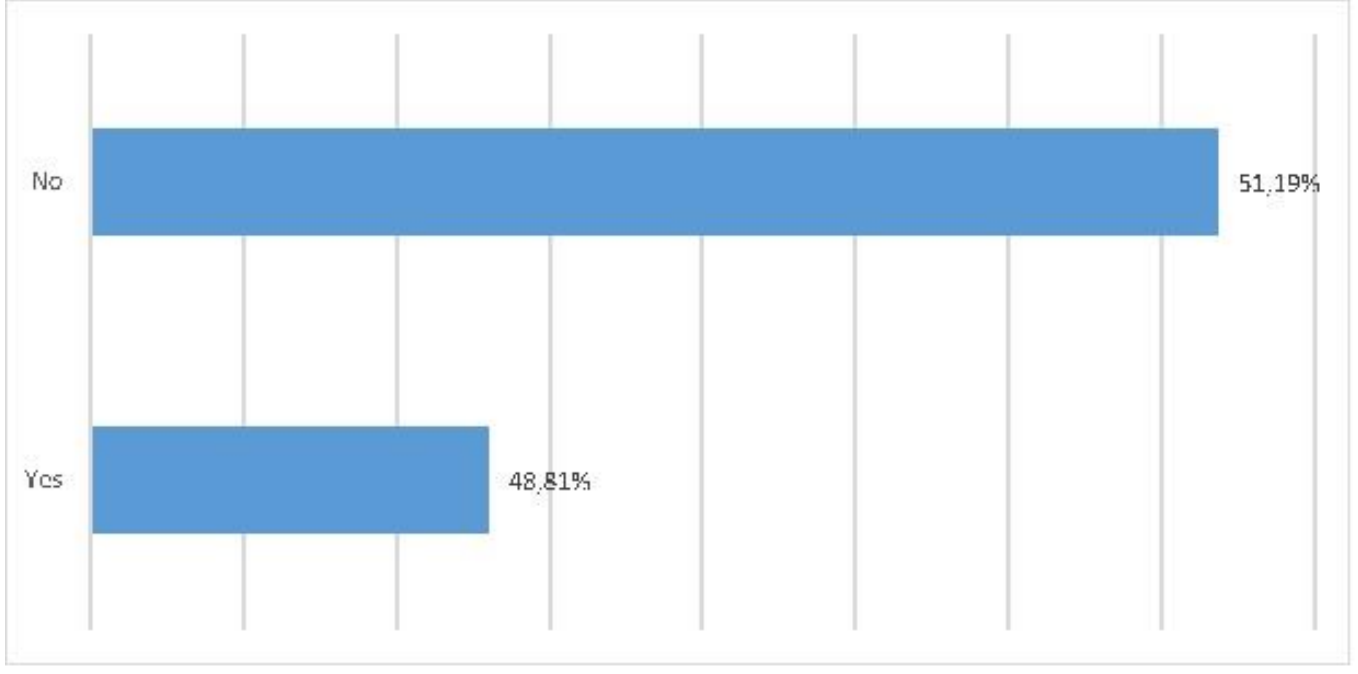

Figure 16: Answ ers to the question „Did you use circular workouts?"

To the question - "What do you know about circular workouts?" - $41.67 \%$ of the students were interested in and have information about the circular workouts, $34.52 \%$ of them have just heard but they have no information about this kind of workout, and $23.81 \%$ know nothing about circuit workouts. The results are presented graphically in Figure 17.

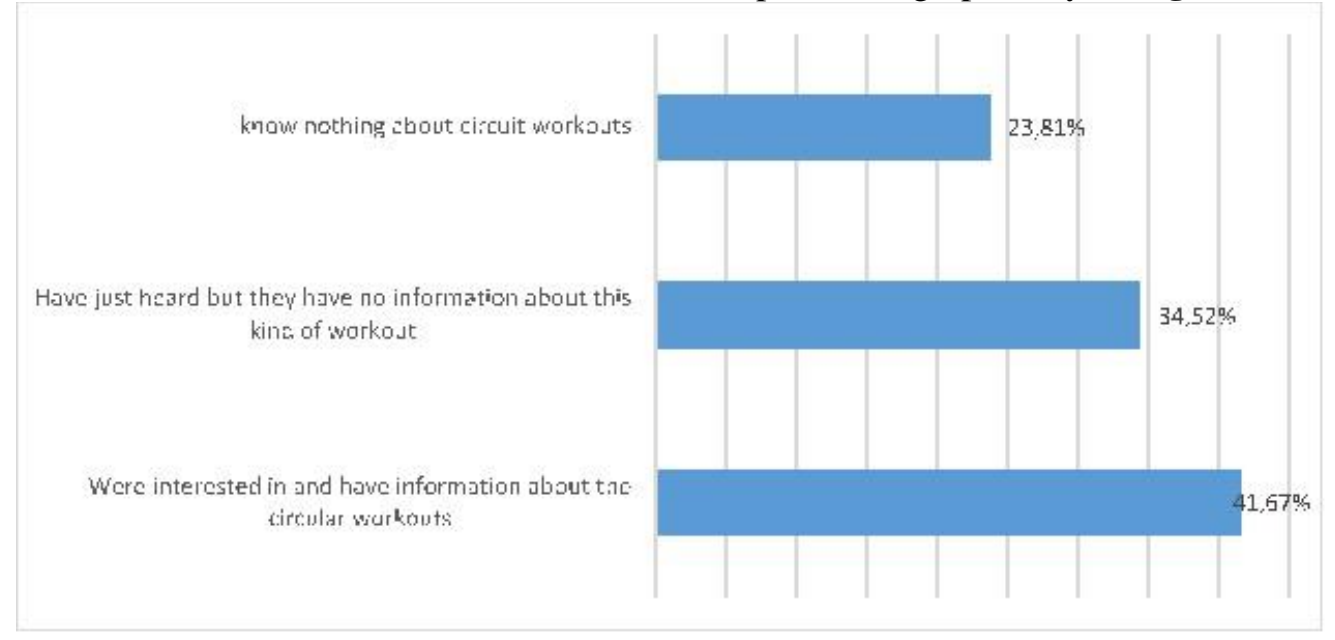

Figure 17: Answers to the question „What do you know about circular w orkouts?"

\section{CONCLUSIONS}

1. The results of the survey showed that the students have a positive attitude towards the physical education and sports classes.

2. There is insufficient awareness of the students about all the benefits of exercise and sports.

3. Due to the heavy workload of the learning process, students do not have free time for additional sports activities.

4. Students' priorities are learning followed by sporting.

5. The factors determining the willingness of students to practice sports are the rational distribution of leisure time and the conditions and accessibility of the sports base.
The recommendations include:

1. Improvement and renovation of the University facilities;

2. Creating prerequisites for inclusion of all students in additional sports activities;

3. Providing theoretical knowledge about the use, effect and benefits of practicing physical exercise and sports;

4. Acquiring knowledge and skills from the students for independent sports activities.

\section{REFERENCES}

1. Bankov P., "Leisure time management", Sofia, 2007

2. Davidov D., "Sportbook for All", NSA, 1995 
3. Yankova N., "Study of Attitude of Students from the NSA" Vasil Levski "to the Optional Course" Power Preparation ", Sofia, 2015

4. Dyakova, G., P. Peeva. (2006) Studying students' attitudes towards the Quick ministep callanetics program and their willingness to deal with it. Ruse University "Angel Kanchev", Scientific papers, ISSN 1311-3321, Volume 45, series 5.4, pp. 7678.

5. Dyakova, D. (2005) Exploring the interest of students in different content in physical education. Sp. Sports and Science, ISSN 1310-3303, S., p. Pc. 1, pp. 628-632.
6. Dyakova, G. (2011) Studying the Attitude of Students to Some Health Factors. Sp. Sports and Science, ISSN 1310-3303, cf. Pc. 1, C., pp. 60-73.

7. Dyakova, G. (2011) Studying the attitude of self-assessment and the self-assessment of the quality of life of students. Sat. "Kinesiology - 2011", VTU "St. St. Cyril and Methodius ", ISSN 1313-244X, pp. 115-119.

8. Milanova P., "Investigation of Some Factors Affecting the Desire of Sports at Students", Sofia, 2011.

9. Hristova N., "Student Attitudes towards Physical Education", Sofia, 2007. 